\title{
Theoretical 3D Model for Quasistatic Critical Derailment Coefficient of Railway Vehicles and a Simplified Formula
}

\author{
Ping Wang $\left(\mathbb{D},{ }^{1,2}\right.$ Jian Wang $\left(\mathbb{D},,^{1,2}\right.$ Xiaochuan Ma $(\mathbb{D}),{ }^{1,2}$ Daolin Ma $\left(\mathbb{D},{ }^{1,2}\right.$ \\ Jingmang Xu $(1),{ }^{1,2}$ and Yao Qian ${ }^{1,2}$ \\ ${ }^{1}$ MOE Key Laboratory of High-Speed Railway Engineering, Southwest Jiaotong University, Chengdu 610031, China \\ ${ }^{2}$ School of Civil Engineering, Southwest Jiaotong University, Chengdu 610031, China
}

Correspondence should be addressed to Daolin Ma; madaolin@swjtu.edu.cn

Received 2 October 2017; Accepted 21 December 2017; Published 17 January 2018

Academic Editor: Stefan Balint

Copyright (C) 2018 Ping Wang et al. This is an open access article distributed under the Creative Commons Attribution License, which permits unrestricted use, distribution, and reproduction in any medium, provided the original work is properly cited.

The formula for the critical derailment coefficient concerning wheelset yaw angles and wheel-rail creep forces is deduced based on the three-dimensional (3D) force equilibrium relationship in the critical wheel derailment state under quasistatic assumption. The change of critical derailment coefficient and wheel-rail contact patch normal force/creep force as wheelset yaw angles change under the influence of the friction coefficient, maximum flange angle, and net wheel weight is analyzed according to the Kalker linear creep theory and Shen-Hedrick-Elkins creep theory. Analysis shows that the wheel-rail friction coefficient and maximum wheel flange contact angle can significantly influence the critical wheel derailment coefficient, further proving the conservative results when the critical Nadal derailment coefficient is adopted in analyzing wheel derailment under small wheelset yaw angles. To realize easy calculation and application of critical 3D derailment coefficients, the ratio of lateral creep force to longitudinal creep force of wheel-rail contact patches under critical quasistatic wheel derailment conditions is deduced. A simplified calculation method of critical derailment coefficients is presented based on this. The calculation accuracy is verified, proving that it can satisfy engineering application.

\section{Introduction}

Safety is the most important issue of rail transportation, and preventing derailment is a fundamental requirement for ensuring safe rail transportation. The openness of constraints between wheels and rails determines the objective existence of vehicle derailment. Derailment has been a problem throughout the development of rail transportation. However, considering the complexity of the wheel-rail system, no full explanation has been presented for the mechanism of vehicle derailment. As rail transportation becomes faster and heavier loads are carried, derailments can produce disastrous results; further understanding of derailment has become more and more important.

As far back as 1896, Nadal, a French scientist [1] derived the force equilibrium conditions of the contact points when wheels show a tendency to climb on the rails under quasistatic assumption according to Coulomb's friction law and introduced the famous Nadal derailment evaluation criterion.
However, in 1976, Gilchrist and Brickle [2] reviewed the Nadal derailment evaluation criterion according to the Hertz contact theory and Duvorol creep force table, pointing out that it, to a certain extent, was conservative under small wheel-rail attack angles and agreed that the Nadal derailment evaluation criterion was appropriate in evaluating derailment under large wheel-rail attack angles. Sweet and Karmel [35] simulated wheel derailment under quasistatic assumption according to the two-degree-of-freedom (2-DOF) and threedegree-of-freedom (3-DOF) dynamic wheelset derailment models and obtained consistent results compared with those of the 1:5 single wheelset derailment model test. Weinstock [6] suggested that rail derailment was related to not only the derailment coefficient at the flange contact side but also the derailment coefficient at the nonflange contact. Therefore, he pointed out that the sum of the derailment coefficients at both sides of the wheelset could be adopted as a criterion in evaluating wheel derailment, and, to a certain extent, corrected the conservative Nadal derailment 
evaluation criterion under small attack angles. Elkins and Shust $[7,8]$ investigated the influence of friction coefficient and wheel-rail attack angle on rail climbing of wheels. They argued that rail climbing of wheels depended on the vehicle running distance when derailment coefficient is out of safe region rather than the duration of the unsafe derailment coefficient. Barbosa $[9,10]$ comprehensively considered the wheel-rail creep action based on a 3D wheel derailment model established under quasistatic assumption and accordingly improved the Nadal derailment evaluation criterion that was conservative under small wheel-rail attack angles. Braghin et al. [11] studied the derailment of single wheelsets through a rolling rig, and, based on theoretical research, pointed out that the derailment evaluation criterion requiring longitudinal creep forces and attack angles was a new concept for measuring derailment coefficients. Zeng and $\mathrm{Wu}$ [12] analyzed the $3 \mathrm{D}$ force equilibrium conditions of wheelsets during derailment and presented the derailment evaluation criterion concerning both wheelset derailment coefficient and wheel load reduction rate. Kuo and Lin [13], based on the Weinstock derailment criterion as well as the force equilibrium conditions of wheelset surfaces, introduced a new derailment evaluation criterion and corrected those deficiencies of the Weinstock derailment criterion.

Although many studies have been presented, the problem of vehicle derailment has still not been solved and different derailment evaluation criteria still do not satisfactorily coincide with each other. To further understand mechanism of derailment, we carried out this research. In this paper, we establish the force analyzing framework of 3-dimensional critical wheel quasistatic derailment in Section 2. Then the formula of the critical derailment coefficient is deduced, and the change of critical derailment coefficient and normal force/creep force of wheel-rail contact patches with wheelset yaw angles under the influence of the friction coefficient, maximum flange angle, and net wheel weight are analyzed according to the Kalker linear creep theory and ShenHedrick-Elkins creep theory, as shown in Sections 3 and 4. In addition, to realize fast calculation and application of critical 3D derailment coefficients, we present a simplified calculation method of critical derailment coefficients in Section 5. Finally, conclusions are addressed in Section 6.

\section{Quasistatic Wheel Derailment Analysis Model}

2.1. Coordinates of Wheel-Rail System. The wheel-rail contact relation is a link for coupling wheels and rails, while the coordinates of a wheel-rail system are crucial for establishing the wheel-rail relation. Figure 1 shows the rail coordinates $\left(O_{T^{-}} X_{T^{-}} Y_{T}-Z_{T}\right)$, wheelset coordinates $\left(O_{w}-X_{w}-Y_{w}-Z_{w}\right)$, and wheel-rail contact patch coordinates $\left(O_{L, R}-X_{L, R}-Y_{L, R}-Z_{L, R}\right)$. The rail coordinates are fixed on the central line of the rail and move along the central line of the rail at a certain speed $V$. The wheelset coordinates are fixed on the centroid of the wheelset. They move with the wheelset and have rotational and translational DOFs (degrees of freedom) in relation to the rail coordinates; the contact patch coordinates are fixed

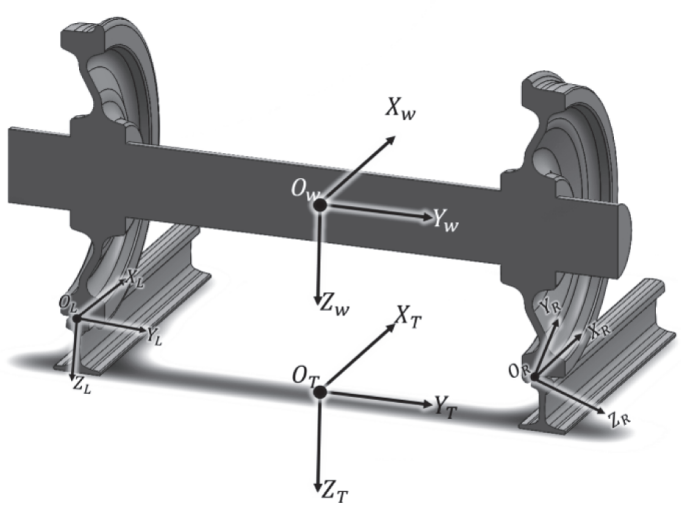

FIgURE 1: Coordinates of wheel-rail system.

on the center of the wheel-rail contact patch and move with the wheelset.

Transform relation between wheelset coordinates and rail coordinates is

$$
\left\{\begin{array}{l}
i_{T} \\
j_{T} \\
k_{T}
\end{array}\right\}=\left[\begin{array}{ccc}
\cos \psi & -\sin \psi & 0 \\
\sin \psi \cos \phi & \cos \psi \cos \phi & -\sin \phi \\
\sin \psi \sin \phi & \cos \psi \sin \phi & \cos \phi
\end{array}\right]\left\{\begin{array}{l}
i_{w} \\
j_{w} \\
k_{w}
\end{array}\right\},
$$

where $\psi$ is the wheelset yaw angle; $\phi$ is the wheelset rolling angle; $\left[i_{T}, j_{T}, k_{T}\right]^{T}$ is the direction vector of the rail coordinates; $\left[i_{w}, j_{w}, k_{w}\right]^{T}$ is the direction vector of the wheelset coordinates.

Transform relation between the left/right wheel-rail contact patch coordinates and wheelset coordinates is

$$
\begin{gathered}
\left\{\begin{array}{l}
i_{w} \\
j_{w} \\
k_{w}
\end{array}\right\}=\left[\begin{array}{ccc}
1 & 0 & 0 \\
0 & \cos \delta_{L} & -\sin \delta_{L} \\
0 & \sin \delta_{L} & \cos \delta_{L}
\end{array}\right]\left\{\begin{array}{l}
i_{L} \\
j_{L} \\
k_{L}
\end{array}\right\} \\
\left\{\begin{array}{l}
i_{w} \\
j_{w} \\
k_{w}
\end{array}\right\}=\left[\begin{array}{ccc}
1 & 0 & 0 \\
0 & \cos \delta_{R} & \sin \delta_{R} \\
0 & -\sin \delta_{R} & \cos \delta_{R}
\end{array}\right]\left\{\begin{array}{l}
i_{R} \\
j_{R} \\
k_{R}
\end{array}\right\},
\end{gathered}
$$

where $\delta_{L}$ and $\delta_{R}$ are the wheel contact angles of the left and right wheel-rail contact points, respectively; $\left[i_{L}, j_{L}, k_{L}\right]^{T}$, $\left[i_{R}, j_{R}, k_{R}\right]^{T}$ are the direction vectors of the left/right wheelrail contact patch coordinates.

The transform relation between the contact point coordinates and rail coordinates is the following after substituting (2) into (1):

$$
\left\{\begin{array}{l}
i_{T} \\
j_{T} \\
k_{T}
\end{array}\right\}=T_{L, R}\left\{\begin{array}{l}
i_{L, R} \\
j_{L, R} \\
k_{L, R}
\end{array}\right\}
$$

where $T_{L, R}$ is the rotation matrix between the contact patch coordinates and rail coordinates 


$$
T_{L, R}=\left[\begin{array}{ccc}
\cos \psi & -\sin \psi \cos \delta_{L, R} & \pm \sin \psi \sin \delta_{L, R} \\
\sin \psi \cos \phi & \cos \psi \cos \phi \cos \delta_{L, R} \mp \sin \phi \sin \delta_{L, R} & \mp \cos \psi \cos \phi \sin \delta_{L, R}-\sin \phi \cos \delta_{L, R} \\
\sin \psi \sin \phi & \cos \psi \sin \phi \cos \delta_{L, R} \pm \cos \phi \sin \delta_{L, R} & \mp \cos \psi \sin \phi \sin \delta_{L, R}+\cos \phi \cos \delta_{L, R}
\end{array}\right] .
$$

Since $\psi$ and $\phi$ are small, $T_{L, R}$ can be simplified as follows:

$$
\begin{aligned}
& T_{L, R} \\
& \quad=\left[\begin{array}{ccc}
1 & -\psi \cos \delta_{L, R} & \pm \psi \sin \delta_{L, R} \\
\psi & \cos \delta_{L, R} \mp \phi \sin \delta_{L, R} & \mp \sin \delta_{L, R}-\phi \cos \delta_{L, R} \\
0 & \phi \cos \delta_{L, R} \pm \sin \delta_{L, R} & \mp \phi \sin \delta_{L, R}+\cos \delta_{L, R}
\end{array}\right] .
\end{aligned}
$$

2.2. Forces on Contact Patch and Critical Derailment Coefficient. Suppose the right wheel of the wheelset is about to derail and its flange contacts with the side surface of the rail; see Figure 2. In this figure, $F, Q$, and $P$ are the longitudinal force, lateral force, and vertical force on the contact point in the rail coordinate system, respectively. $T_{x}, T_{y}$, and $N$ are the longitudinal creep force, lateral creep force, and normal force on the contact patch in the contact patch coordinate system, respectively.

According to the force equilibrium conditions on the wheel-rail contact patch as well as the transform relation between the rail coordinates and wheel-rail contact patch coordinates, we obtain

$$
\left\{\begin{array}{l}
F \\
Q \\
P
\end{array}\right\}+T_{R}\left\{\begin{array}{c}
T_{x} \\
T_{y} \\
-N
\end{array}\right\}=0
$$

The ratio of the wheel-rail lateral force to the vertical force at the contact patch can be obtained according to (5):

$$
\frac{Q}{P}=\frac{-T_{x} \sin \psi \cos \phi-T_{y}\left(\cos \psi \cos \phi \cos \delta_{R}+\sin \theta \sin \delta_{R}\right)+N\left(\cos \psi \cos \phi \sin \delta_{R}-\sin \phi \cos \delta_{R}\right)}{-T_{x} \sin \psi \sin \phi-T_{y}\left(\cos \psi \sin \phi \cos \delta_{R}-\cos \phi \sin \delta_{R}\right)+N\left(\cos \psi \sin \phi \sin \delta_{R}+\cos \phi \cos \delta_{R}\right)} .
$$

Since the yaw angle and rolling angle are small, then (7) can be further simplified as

$$
\frac{Q}{P}=\frac{-T_{y} \cos \delta_{R}+N \sin \delta_{R}}{T_{y} \sin \delta_{R}+N \cos \delta_{R}}
$$

where the ratio of lateral wheel-rail force to vertical force is called the derailment coefficient (DC) of the wheels. When the flange contact angle $\delta_{R}$ reaches the maximum, the gradient at this position during rail climbing will be the highest, the resistance for the wheels during rail climbing will be the highest and the wheels will be liable to derail when passing this position. Therefore, when $\delta_{R}$ is the maximum flange contact angle, the derailment coefficient is considered as the critical value of wheel derailment.

Nadal thought that when the wheels were subject to a critical derailment state, the wheel-rail tangential force would satisfy Coulomb's friction law. He used a two-dimensional (2D) model for analyzing derailment, so the contribution of the longitudinal creep force to the tangential force was ignored, then

$$
T_{y}=\mu N
$$

where $\mu$ is the wheel-rail friction coefficient.

The formula of critical Nadal derailment coefficient can be obtained by substituting (9) in (8):

$$
\frac{Q}{P}(\text { Nadal })=\frac{-\mu+\tan \delta_{R}}{\mu \tan \delta_{R}+1} .
$$

\section{Calculation of Creep Force}

Under quasistatic assumption, when the wheelset speed and acceleration are ignored, the wheel-rail rigid creepage can be calculated according to the following [14]:

$$
\begin{aligned}
& \xi_{x}=1-\frac{r_{w R}}{r_{0}} \\
& \xi_{y}=-\psi \sec \delta_{R} \\
& \xi_{s}=-\frac{\sin \delta_{R}}{r_{0}},
\end{aligned}
$$

where $\xi_{x}, \xi_{y}$, and $\xi_{s}$ are the longitudinal creepage, lateral creepage, and spin creepage, respectively. $r_{w R}$ is the real rolling radius of the wheels at the right wheel-rail contact point, while $r_{0}$ is the nominal rolling radius of the wheels. According to (11), the creepage obtained under quasistatic assumption relates only to the wheel-rail contact geometric parameter.

According to the Kalker linear creep theory [15], the relation between the creep force and creepage can be expressed as follows:

$$
\left[\begin{array}{c}
T_{x}^{\prime} \\
T_{y}^{\prime} \\
M^{\prime}
\end{array}\right]=E a b\left[\begin{array}{ccc}
C_{11} & 0 & 0 \\
0 & C_{22} & \sqrt{a b} C_{23} \\
0 & -\sqrt{a b} C_{23} & a b C_{33}
\end{array}\right]\left[\begin{array}{c}
\xi_{x} \\
\xi_{y} \\
\xi_{s}
\end{array}\right]
$$


TABLE 1: Relation between creep coefficient and $a / b$.

\begin{tabular}{lccccccccccc}
\hline$a / b$ & 0.1 & 0.2 & 0.3 & 0.4 & 0.5 & 0.6 & 0.7 & 0.8 & 0.9 & - \\
\hline C11 & 3.31 & 3.37 & 3.44 & 3.53 & 3.62 & 3.72 & 3.81 & 3.91 & 4.01 & - \\
C22 & 2.52 & 2.63 & 2.75 & 2.88 & 3.01 & 3.14 & 3.28 & 3.41 & 3.54 & - \\
C23 & 0.473 & 0.603 & 0.715 & 0.823 & 0.929 & 1.03 & 1.14 & 1.25 & 1.36 & - \\
C33 & 8.82 & 4.27 & 2.96 & 2.32 & 1.93 & 1.68 & 1.50 & 1.37 & 1.27 & - \\
\hline$b / a$ & 1.0 & 0.9 & 0.8 & 0.7 & 0.6 & 0.5 & 0.4 & 0.3 & 0.2 & 0.1 \\
\hline C11 & 4.12 & 4.22 & 4.36 & 4.54 & 4.78 & 5.10 & 5.57 & 6.34 & 7.78 & 11.7 \\
C22 & 3.67 & 3.81 & 3.99 & 4.21 & 4.50 & 4.90 & 5.48 & 6.40 & 8.14 & 12.8 \\
C23 & 1.47 & 1.59 & 1.75 & 1.95 & 2.23 & 2.62 & 3.24 & 4.23 & 6.63 & 14.6 \\
C33 & 1.19 & 1.11 & 1.04 & 0.965 & 0.892 & 0.819 & 0.747 & 0.674 & 0.601 & 0.526 \\
\hline
\end{tabular}

TABLE 2: Relation between $m / n$ and $\theta$.

\begin{tabular}{ccccccccc}
\hline$\theta$ & $0^{\circ}$ & $10^{\circ}$ & $20^{\circ}$ & $30^{\circ}$ & $35^{\circ}$ & $40^{\circ}$ & $45^{\circ}$ & $50^{\circ}$ \\
\hline$m$ & $\infty$ & 6.612 & 3.778 & 2.731 & 2.397 & 2.130 & 1.926 & 1.754 \\
$n$ & 0 & 0.319 & 0.408 & 0.493 & 0.530 & 0.567 & 0.604 & 0.641 \\
\hline$\theta$ & $55^{\circ}$ & $60^{\circ}$ & $65^{\circ}$ & $70^{\circ}$ & $75^{\circ}$ & $80^{\circ}$ & $85^{\circ}$ & $90^{\circ}$ \\
\hline$m$ & 1.611 & 1.486 & 1.378 & 1.284 & 1.202 & 1.128 & 1.061 & 1.000 \\
$n$ & 0.678 & 0.717 & 0.759 & 0.802 & 0.846 & 0.893 & 0.944 \\
\hline
\end{tabular}

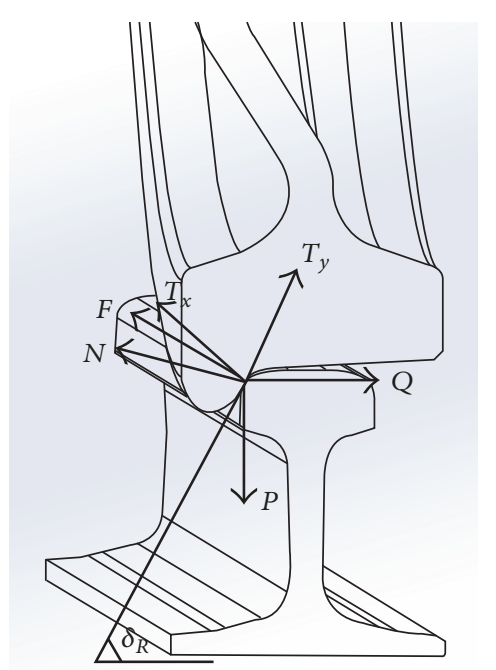

FIGURE 2: Forces on contact patch.

where $T_{x}^{\prime}, T_{y}^{\prime}$, and $M^{\prime}$ are the Kalker linear longitudinal/lateral creep force and spin creep force, respectively; $E$ is Young's modulus of the wheel and rail materials; $a$ and $b$ are the longitudinal and lateral semiaxle lengths of the Hertz elliptical contact patch, respectively; $C_{11}, C_{22}, C_{23}$, and $C_{33}$ are the Kalker creep coefficients relating to the ratio of $a$ and $b$, which are shown in Table 1 .

According to the Hertz contact theory, the longitudinal/lateral semiaxle $a$ and $b$ of the elliptical wheel-rail contact patch are

$$
a=m\left[\frac{3\left(1-\sigma^{2}\right)}{2 E(A+B)} N\right]^{1 / 3}
$$

$$
b=n\left[\frac{3\left(1-\sigma^{2}\right)}{2 E(A+B)} N\right]^{1 / 3}
$$

where $\sigma$ is Poisson's ratio, $m$ and $n$ are the semiaxle correction coefficients of the ellipses, which can obtained according to $\theta$ of (14) and Table 2:

$$
\theta=\arccos \left|\frac{B-A}{A+B}\right|
$$

where

$$
\begin{aligned}
& A+B=\frac{1}{2}\left(\frac{1}{R_{T R}}+\frac{1}{R_{w R}}+\frac{1}{r_{w R}}\right) \\
& B-A=\frac{1}{2}\left|\frac{1}{R_{T R}}-\frac{1}{R_{w R}}-\frac{1}{r_{w R}}\right|,
\end{aligned}
$$

where $R_{T R}$ and $R_{w R}$ are the radii of the rail and wheel profile at the wheel-rail contact.

The Kalker linear creep force model is only suitable when the creep is low since it is supposed that no relative slip occurs in the contact patch. Under flange contact, the creepage increases, and even a full slip state can occur in the contact patch, so the linear creep force must be corrected. In this paper, the Shen-Hedrick-Elkins nonlinear creep model [16] has been used for correcting the wheel-rail creep force; see the following:

$$
\left[\begin{array}{c}
T_{x} \\
T_{y} \\
M
\end{array}\right]=\frac{T_{s}}{T_{s}^{\prime}}\left[\begin{array}{c}
T_{x}^{\prime} \\
T_{y}^{\prime} \\
M^{\prime}
\end{array}\right]
$$


TABLE 3: Wheel-rail contact parameters obtained under critical derailment conditions.

\begin{tabular}{lcccccccc}
\hline$P$ & $E$ & $\delta_{R}$ & $\sigma$ & $r_{0}$ & $r_{R}$ & $R_{W R}$ & $R_{T R}$ \\
\hline $70 \mathrm{kN}$ & $2.06 \times 10^{5} \mathrm{Mpa}$ & $70^{\circ}$ & 0.25 & $0.4575 \mathrm{~m}$ & $0.475 \mathrm{~m}$ & $0.014 \mathrm{~m}$ & $0.013 \mathrm{~m}$ & 0.25 \\
\hline
\end{tabular}

where $T_{s}^{\prime}$ is the comprehensive creep force calculated according to the Kalker linear creep theory; see (17); $T_{s}$ is the corrected comprehensive creep force; see (18).

$$
T_{s}^{\prime}=\sqrt{T_{x}^{\prime}+T_{y}^{\prime}}
$$

$T_{s}$

$$
= \begin{cases}\mu N\left[\frac{T_{s}^{\prime}}{\mu N}-\frac{1}{3}\left(\frac{T_{s}^{\prime}}{\mu N}\right)^{2}+\frac{1}{27}\left(\frac{T_{s}^{\prime}}{\mu N}\right)^{3}\right], & T_{s}^{\prime} \leq 3 \mu N \\ \mu N, & T_{s}^{\prime}>3 \mu N .\end{cases}
$$

According to the wheel-rail creep force calculation model, when the wheel-rail contact parameter and wheelset yaw angle are given, the creep force only relates to the normal force. Since contact point vertical force equilibrium can be obtained based on (6), then

$$
\begin{gathered}
T_{y}(N)\left(\phi \cos \delta_{R}+\sin \delta_{R}\right)+N\left(\cos \delta_{R}-\phi \sin \delta_{R}\right) \\
-P=0
\end{gathered}
$$

The following can be obtained when the rolling angle is ignored:

$$
T_{y}(N) \sin \delta_{R}+N \cos \delta_{R}-P=0 .
$$

When the wheel-rail vertical force $P$ is given, the wheelrail normal force $N$ can be calculated by way of iteration according to (20) and Shen-Hedrick-Elkins nonlinear creep model and then the creep force and critical derailment coefficient can be obtained.

\section{Results and Discussion}

Table 3 shows the wheel-rail contact parameters obtained under quasistatic critical wheel derailment conditions. The wheel-rail force and critical derailment coefficient as the wheelset yaw angle changes are shown in Figures 3 and 4 .

As shown in Figure 3, when the wheelset yaw angle is a negative value, the wheel-rail normal force will significantly increase with the increase of the wheelset yaw angle. When the yaw angle increases from $0^{\circ}$ to $-1.5^{\circ}$, the wheel-rail normal force will linearly increase. With the increase of the wheelset yaw angle, the longitudinal creep force will increase and then decrease and reach the maximum when the yaw angle is about $-0.5^{\circ}$. The lateral creep force is a negative value and increases significantly with the increase of the wheelset yaw angle, indicating that it is opposite to the wheel derailment direction shown in Figure 2 and hinders the wheel derailment. This mode is called wheel-slide derailment. When the wheelset yaw angle is a positive value, the wheelrail normal force and longitudinal creep force, to a certain

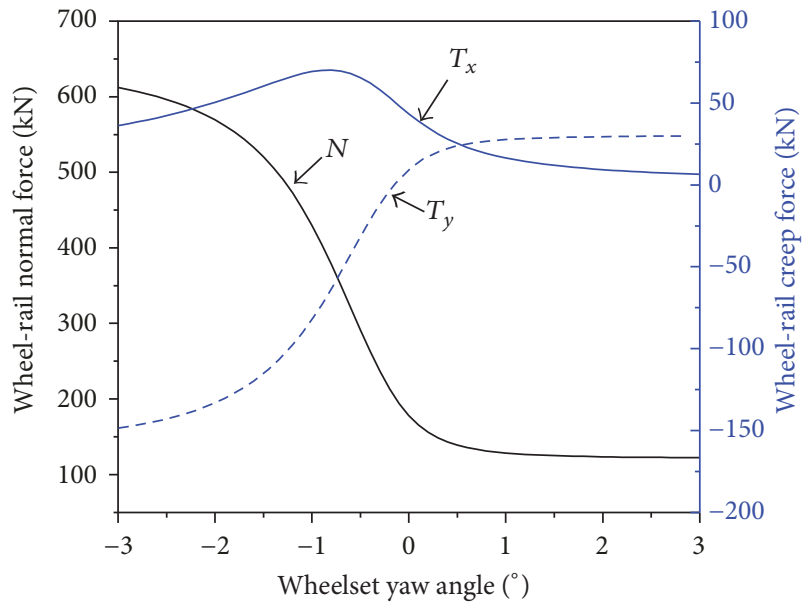

FIGURE 3: Wheel-rail force of contact patch under critical derailment.

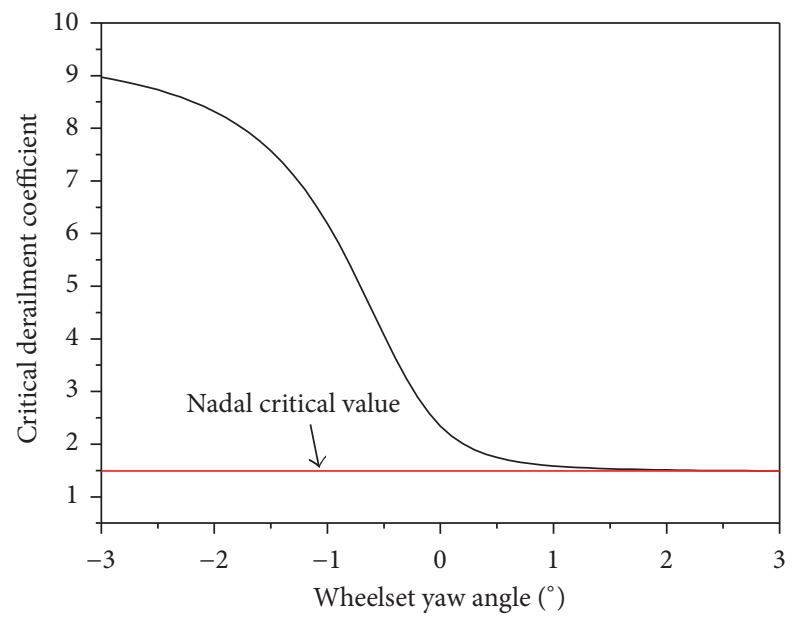

FIgURE 4: Critical derailment coefficient.

extent, decrease with the increase of the wheelset yaw angle; however when the wheelset yaw angle is over $1.5^{\circ}$, their amplitudes basically do not change. Moreover, when the positive wheelset yaw angle becomes high, the longitudinal creep force basically tends toward 0 . The lateral creep force, to a certain extent, increases with the increase of the wheelset yaw angle, and its amplitude is always positive, coinciding with the wheel derailment direction, indicating that it can prompt wheel derailment. This mode is called wheel-climb derailment.

As shown in Figure 4, the critical derailment coefficient under a negative wheelset yaw angle is significantly higher than that under a positive yaw angle. This means that wheels are liable to derail under positive yaw angles, because the influence of the lateral creep forces on wheel derailment 


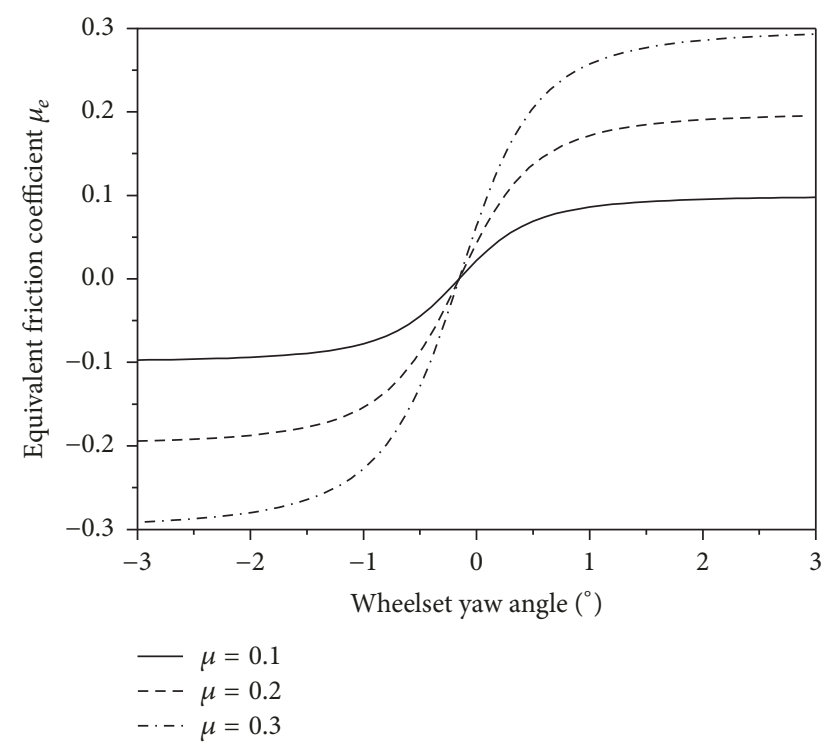

FIGURE 5: Equivalent friction coefficient under different friction coefficients.

under negative wheelset yaw angles is different from that under positive yaw angles. In addition, Figure 4 also shows the ratio of the critical derailment coefficient to the limited Nadal derailment coefficient. It can be seen that when the positive wheelset yaw angle is over $1.5^{\circ}$, their amplitudes are almost the same, because at this time the longitudinal creep force amplitude is close to 0 , and the lateral creep force amplitude is close to the Coulomb friction force. However, when the positive wheelset yaw angle is low or the angle is negative, the limited Nadal derailment coefficient is conservative to a certain extent, because the longitudinal creep force cannot be ignored, and the direction of the lateral creep force must to be considered.

For given profiles of wheels and rails, parameters such as $\sigma, r_{0}, R_{w R}$, and $R_{T R}$ do not change much or influence wheel derailment much during operation. However, the wheel-rail friction coefficient can be significantly influenced by changes of season and weather, and the wheel flange can wear to some extent, causing change of the maximum flange contact angle. In addition, the axle load also significantly changes due to different vehicle loads. Hence, the study should focus on the influence of the above three parameters on the critical derailment coefficient.

Equation (8) can be simplified to be the same as that for calculating the Nadal derailment coefficient for the sake of easy analysis:

$$
\frac{Q}{P}=\frac{-\mu_{e}+\tan \delta_{R}}{\mu_{e} \tan \delta_{R}+1}
$$

where $\mu_{e}=T_{y} / N$, called the equivalent friction coefficient.

Figures 5 and 6 show the influence of changing wheel-rail friction coefficient on the critical derailment coefficient. The equivalent friction coefficient can be decreased by decreasing the wheel-rail friction coefficient; that is, the ratio of lateral creep force to normal force can be decreased. However,

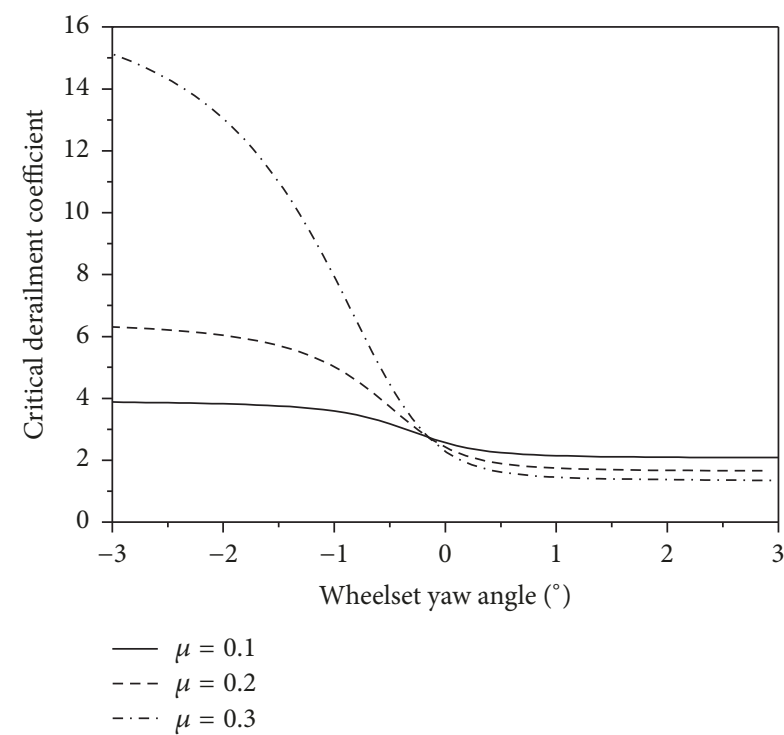

Figure 6: Critical derailment coefficient under different friction coefficients.

the direction of the lateral creep force is the same as that of the wheelset yaw angle, so, under a positive wheelset yaw angle, the positive effect of the lateral creep force on wheel derailment can be reduced by decreasing the wheel-rail friction coefficient, which is beneficial for preventing wheel derailment. However, under a negative wheelset yaw angle, the decrease of wheel-rail friction coefficient can obstruct the positive effect of the lateral creep force on wheel derailment, which is detrimental for preventing wheel derailment. Therefore, care should be taken to prevent wheel derailment through decreasing the wheel-rail friction coefficient. Though an over low friction coefficient is good for reducing derailment risks under a positive yaw angle, the difference between the limited wheel derailment coefficient under a negative yaw angle and the critical derailment coefficient under a positive yaw angle can be reduced, causing possible wheel-slide derailment.

Figures 7 and 8 show the influence of changing maximum flange contact angle on the equivalent friction coefficient and critical derailment coefficient. When the yaw angle is kept within $-1.5^{\circ} \sim 1.5^{\circ}$, the equivalent friction coefficient will increase to a certain extent with the increase of the maximum flange contact angle. However, when the absolute value of the wheelset yaw angle is over $1.5^{\circ}$, the equivalent friction coefficient will basically not change, because when the wheelset yaw angle becomes high, the longitudinal creep force will be close to 0 , and the lateral creep force will be close to the Coulomb friction force. As shown in the figures, no matter whether the wheelset yaw angle is positive or negative, the critical derailment coefficient can increase with the increase of the maximum flange contact angle, reducing the wheel derailment risk.

Figures 9 and 10 show the influence of the wheel load on the equivalent friction coefficient and critical derailment coefficient. It can be seen that the change of wheel load 


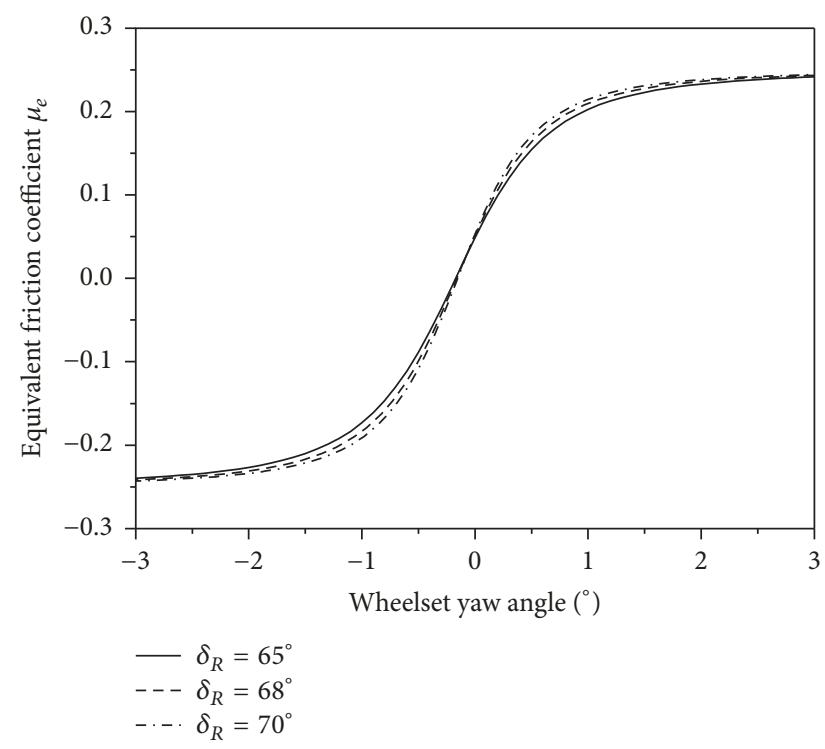

FIGURE 7: Equivalent friction coefficient under different maximum flange contact angles.

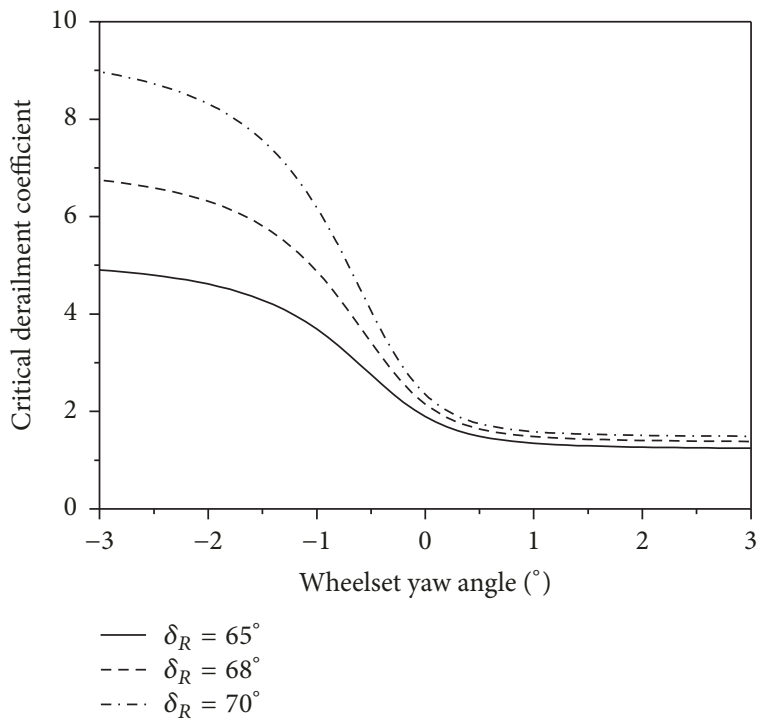

FIgURE 8: Critical derailment coefficient under different maximum flange contact angles.

basically has no influence on the equivalent friction coefficient and critical derailment coefficient.

\section{Simplified Calculation Method}

According to (18), the ratio of the Kalker linear comprehensive creep force to 3 times the Coulomb friction force is a key factor in determining whether the creep of wheel-rail contact patches reaches saturation. The formula presented above depends on many parameters and cannot facilitate further understanding of rail-wheel derailment. In this chapter, we present a simplified calculation model which is easy to use while maintaining accuracy.

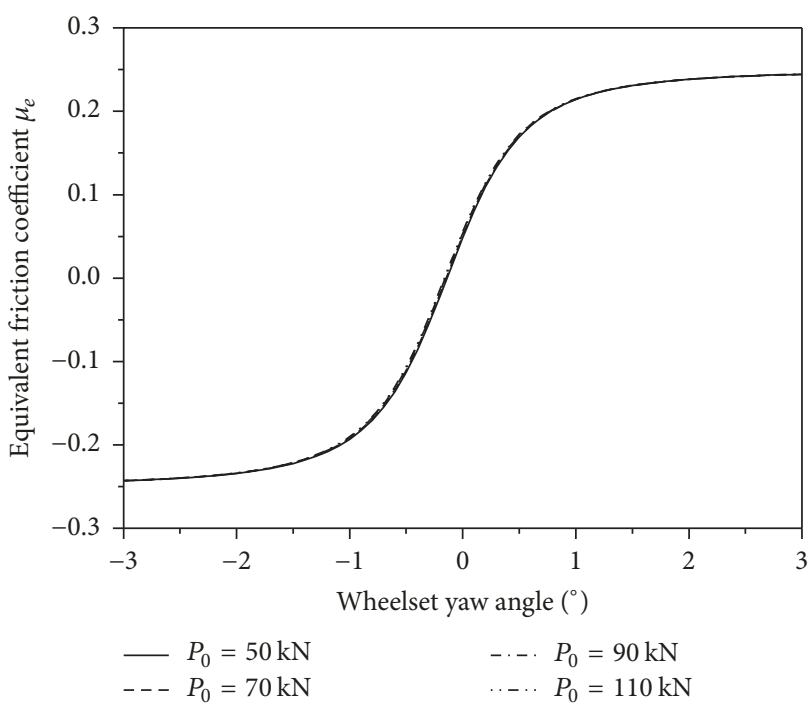

FIGURE 9: Equivalent friction coefficient under different wheel loads.

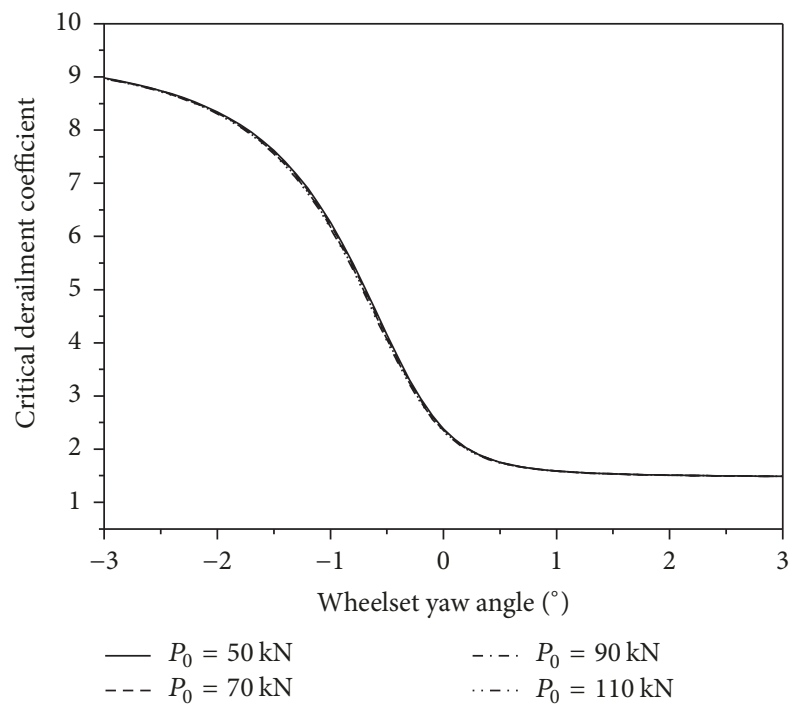

FIGURE 10: Critical derailment coefficient under different wheel loads.

5.1. Presentation of Simplified Calculation Method. Figure 11 shows how the ratio of the Kalker linear comprehensive creep force to 3 times the Coulomb friction force changes with the yaw angle under different friction coefficients, maximum flange contact angles, and net wheel loads. According to the analysis, when the wheelset is subject to critical derailment, all ratios of the comprehensive Kalker linear creep force to 3 times the Coulomb friction force are higher than 1, indicating that the creep force within the wheel-rail contact patch at the flange contact side reaches saturation at that moment.

According to the Shen-Hedrick-Elkins creep theory, when the creep force within the contact patch reaches saturation, the relation between the wheel-rail longitudinal/lateral creep force and normal force is

$$
\sqrt{T_{x}^{2}+T_{y}^{2}}=\mu N \text {. }
$$



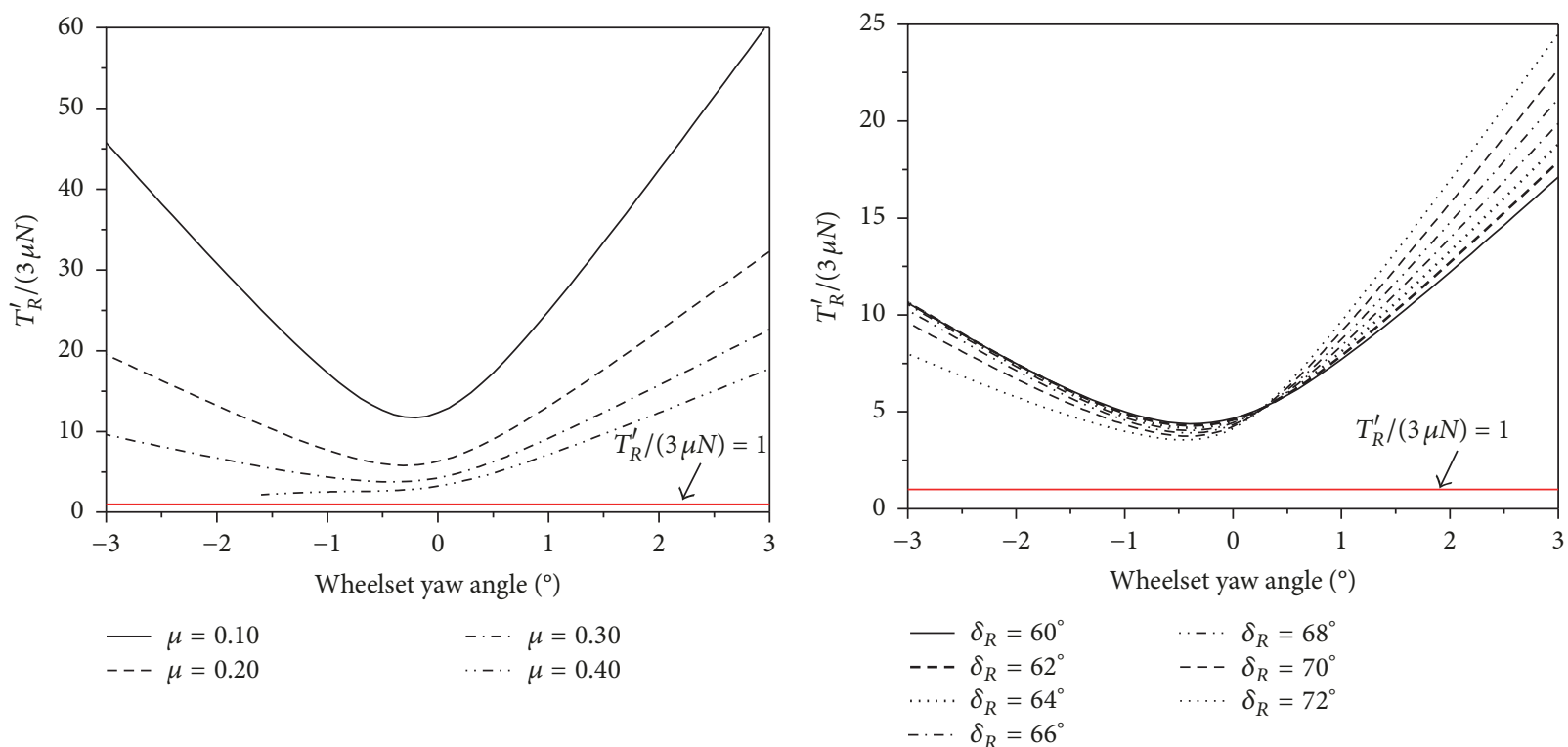

(a)

(b)

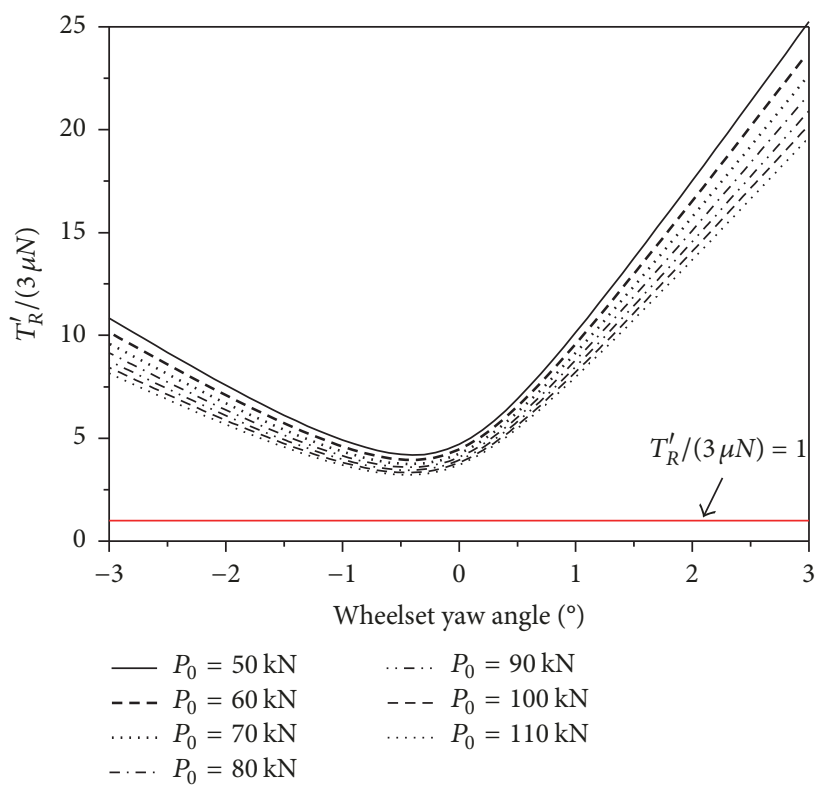

(c)

Figure 11: Ratios of the Kalker linear creep force to 3 times the Coulomb friction force. (a) Different friction coefficients, (b) different maximum flange contact angles, and (c) different net wheel loads. then

Suppose that the included angle between $T_{x}$ and $T_{y}$ is $\alpha$;

$$
\begin{aligned}
\tan \alpha & =\frac{T_{y}}{T_{x}} \\
T_{x} & =\mu N \cos \alpha \\
T_{y} & =\mu N \sin \alpha .
\end{aligned}
$$

Substitute (23) into (21), then the critical derailment coefficient can be expressed as follows:

$$
\frac{Q}{P}=\frac{-\mu_{e}+\tan \delta_{R}}{\mu_{e} \tan \delta_{R}+1}
$$

$$
\mu_{e}=\mu \sin \alpha
$$

The critical derailment coefficient can be calculated according to (24) if the included angle between the longitudinal and lateral creep forces can be obtained. The ratio of the lateral creep force to the longitudinal creep force under critical derailment can be obtained according to (12):

$$
\frac{T_{y}}{T_{x}}=\frac{E a b C_{22} \xi_{y}+E(a b)^{3 / 2} C_{23} \xi_{s}}{E a b C_{11} \xi_{x}}
$$




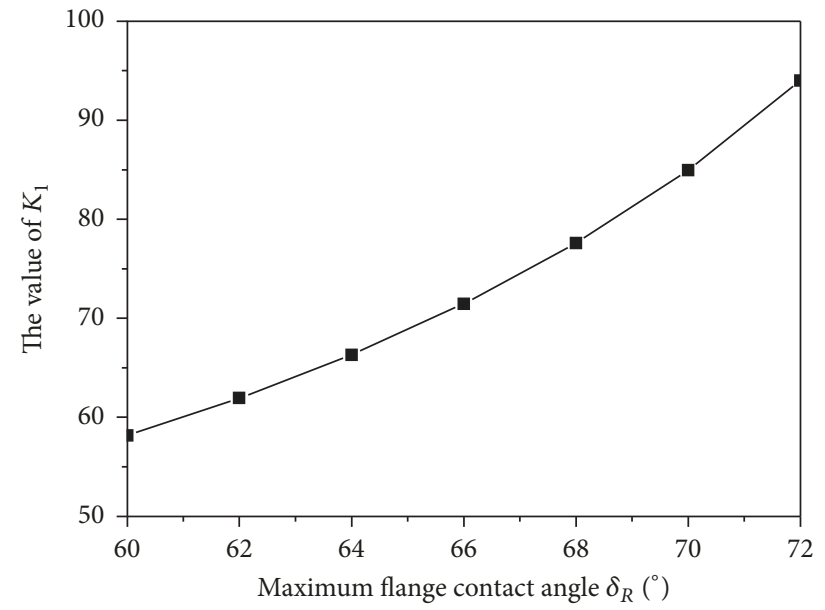

(a)

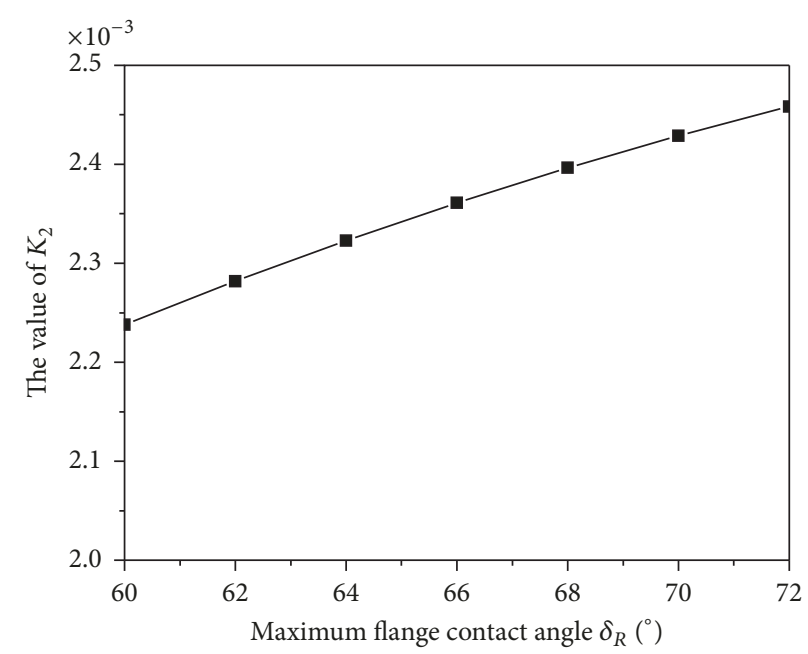

(b)

Figure 12: Amplitudes of $K_{1}$ and $K_{2}$ under different maximum flange contact angles. (a) $K_{1}$; (b) $K_{2}$.

$$
=\frac{C_{22} \xi_{y}+(a b)^{1 / 2} C_{23} \xi_{s}}{C_{11} \xi_{x}}
$$

The following can be obtained by substituting (11) and (13) into (25):

$$
\frac{T_{y}}{T_{x}}=K_{1} \psi+K_{2}(N)^{1 / 3} \text {, }
$$

where

$$
\begin{aligned}
& K_{1}=\frac{C_{22} \sec \delta_{R}}{C_{11}\left(r_{w R} / r_{0}-1\right)}, \\
& K_{2}=\frac{C_{23} \sin \delta_{R}}{C_{11}\left(r_{w R}-r_{0}\right)}(m n)^{1 / 2}\left[\frac{3\left(1-\sigma^{2}\right)}{2 E(A+B)}\right]^{1 / 3} .
\end{aligned}
$$

According to (26), when the contact parameters under critical wheel derailment are known, $K_{1}$ and $K_{2}$ can be determined, and the ratio of the lateral creep force to the longitudinal creep force only relates to the wheelset yaw angle and normal force. Figure 12 shows the amplitudes of $K_{1}$ and $K_{2}$ under different maximum flange contact angles. It can be seen that the amplitude of $K_{1}$ is far higher than that of $K_{2}$, and the maximum flange contact angle can significantly influence $K_{1}$ but does not influence $K_{2}$ much.

In addition to the influence of wheel-rail contact parameters, the ratio of the lateral creep force to the longitudinal creep force can also be influenced by the normal force. According to Section 4, the normal force is mainly influenced by the friction coefficient and maximum flange contact angle. Figure 13 shows how the amplitudes of $K_{1} \psi$ and $K_{2} N^{1 / 3}$ of (26) change with the wheelset yaw angle when the maximum flange contact angles are $60^{\circ}$ and $70^{\circ}$, respectively. According to Figure $13, K_{1}$ is far higher than $K_{2}$, causing the amplitude of $K_{1} \psi$ to be significantly higher than that of $K_{2} N^{1 / 3}$, so it can be deduced that the ratio of the longitudinal creep force and lateral creep force has a strong linear relation to the wheelset yaw angle rather than the friction coefficient.

To verify the above deduction, Figure 14 shows how the ratio of the lateral creep force to the longitudinal creep force changes with the wheelset yaw angle under different friction coefficients when the maximum flange contact angles are $60^{\circ}$ and $70^{\circ}$, respectively. Under a positive wheelset yaw angle, the friction coefficient basically has no influence on their ratio. However, under a negative wheelset yaw angle, the friction coefficient can influence their ratio to some extent, because under the positive attack angle the wheelrail normal force is low and does not change much with the friction coefficient, but, under the negative wheelset yaw angle, the wheel-rail normal force is significantly higher than that under the positive wheelset yaw angle. As a whole, $K_{1}$ is far higher than $K_{2}$ under critical derailment, so the ratio of the lateral creep force to the longitudinal creep force changes with the wheelset yaw angle linearly and intensely and is not influenced much by the friction coefficient, indicating that the deduction of this paper is reasonable and correct.

In order to simplify the calculation of critical derailment coefficient, based on the analysis of the strong linear relation between the lateral creep force and longitudinal creep force under critical derailment, this paper proposed that the linear relationship, as shown in (27), can be adopted to fit the ratio of the lateral creep force to the longitudinal creep force. Figure 15 shows the comparison of this fitting to raw simulation data.

$$
\frac{T_{y}}{T_{x}}=C \psi+D .
$$

The simplified evaluation formula of 3D derailment coefficients limit under quasistatic assumption can be obtained by substituting (28) into (24), as shown in 


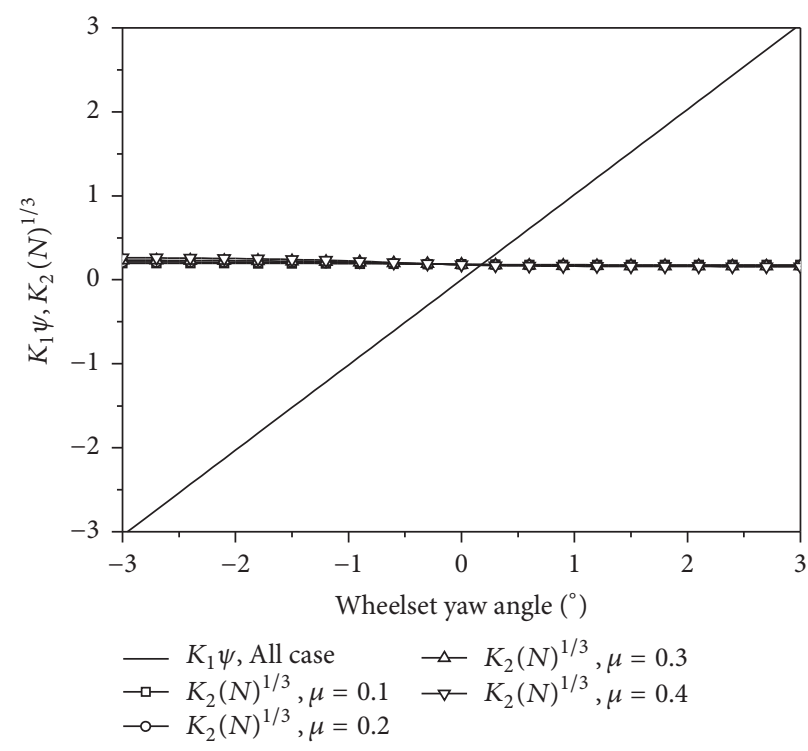

(a)

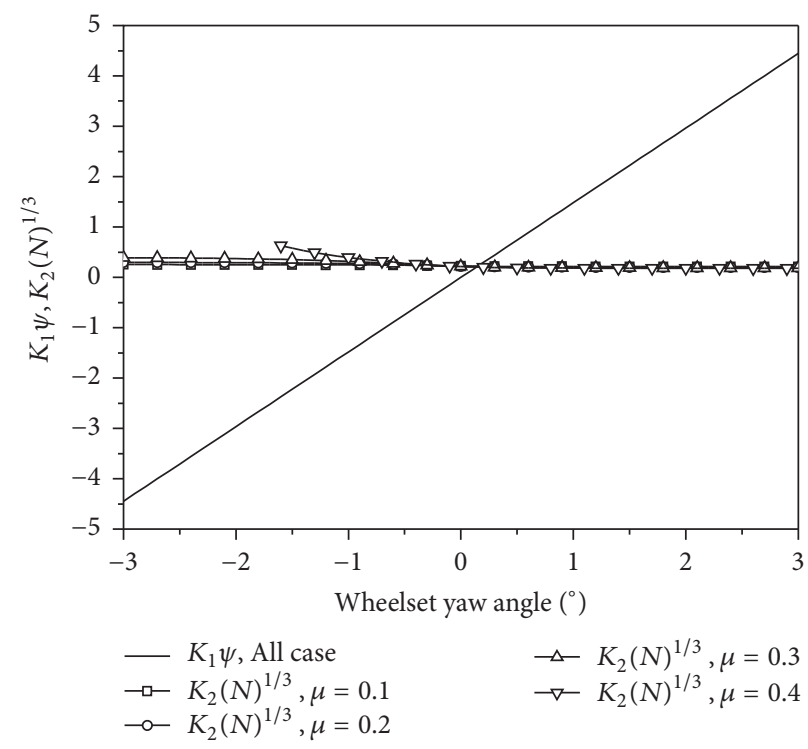

(b)

Figure 13: Amplitudes of $K_{1} \psi$ and $K_{2} N^{1 / 3}$ under different friction coefficients. (a) $\delta_{R}=60^{\circ}$; (b) $\delta_{R}=70^{\circ}$.

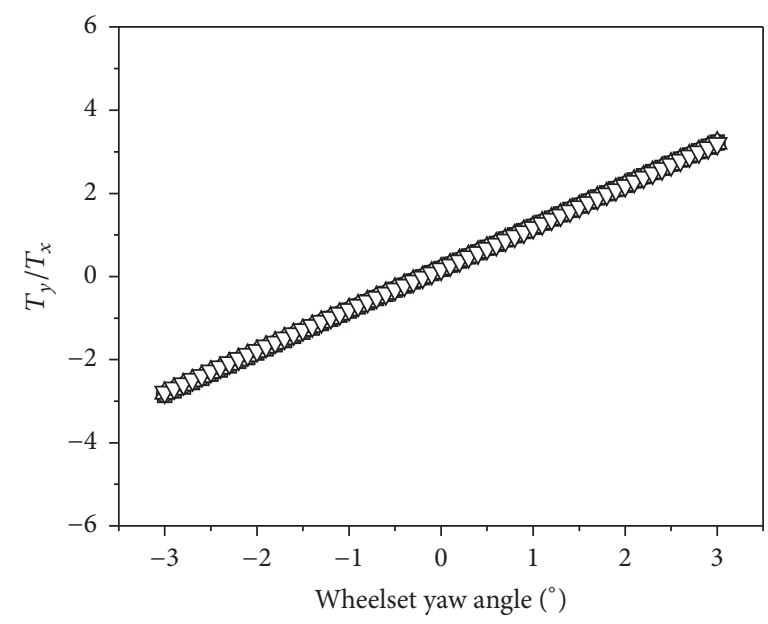

$\square \mu=0.1$

$\circ \mu=0.2$

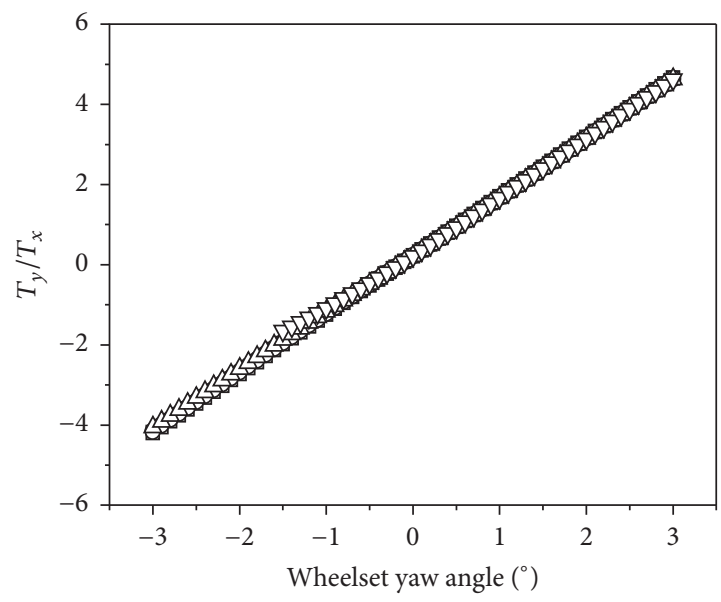

$$
\begin{array}{ll}
\square \mu=0.1 & \triangle \mu=0.3 \\
\circ \mu=0.2 & \nabla \mu=0.4
\end{array}
$$

(b)

FigurE 14: Ratio of lateral creep force to longitudinal creep force. (a) $\delta_{R}=60^{\circ}$; (b) $\delta_{R}=70^{\circ}$.

$$
\begin{aligned}
& \frac{Q}{P}=\frac{-\mu_{e}+\tan \delta_{R}}{\mu_{e} \tan \delta_{R}+1} \\
& \mu_{e}=\mu \frac{C \psi+D}{\sqrt{1+(C \psi+D)^{2}}} .
\end{aligned}
$$

5.2. Verification of Accuracy. To verify the difference between the critical derailment coefficients calculated according to the simplified derailment coefficient calculation method and the accurate calculation method, Figure 16 shows the comparison between them under different wheelset yaw angle and friction coefficients. The errors between them is calculated according to (30), as shown in Figure 17.

$$
\text { Error rate }=\frac{\text { formula }(29)-\text { formula }(8)}{\text { formula }(8)} 100 \% \text {. }
$$

As shown in Figure 16, the critical derailment coefficients calculated according to the simplified formula (29) mentioned in this paper and the quasistatic formula (8) under critical derailment conditions are close to each other, especially when the wheelset yaw angle is high, and the two results approach each other. As shown in Figure 17, with increase of the friction coefficient, the error rate between the critical derailment coefficients calculated according to the simplified formula (29) and the quasistatic formula (8) under critical derailment conditions will increase to a certain extent; however, both of the errors are controllable within $-5 \% \sim 5 \%$, 


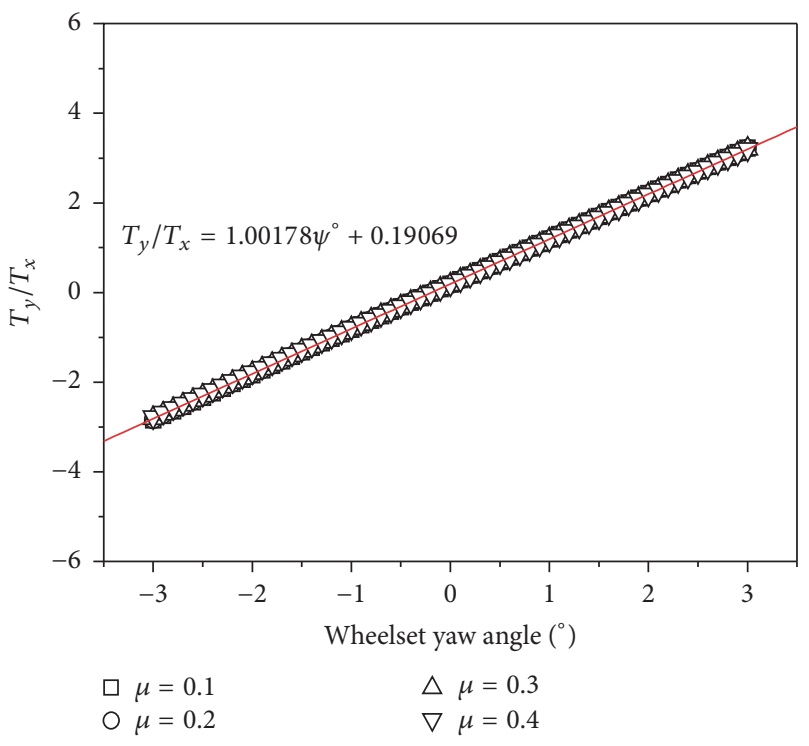

(a)

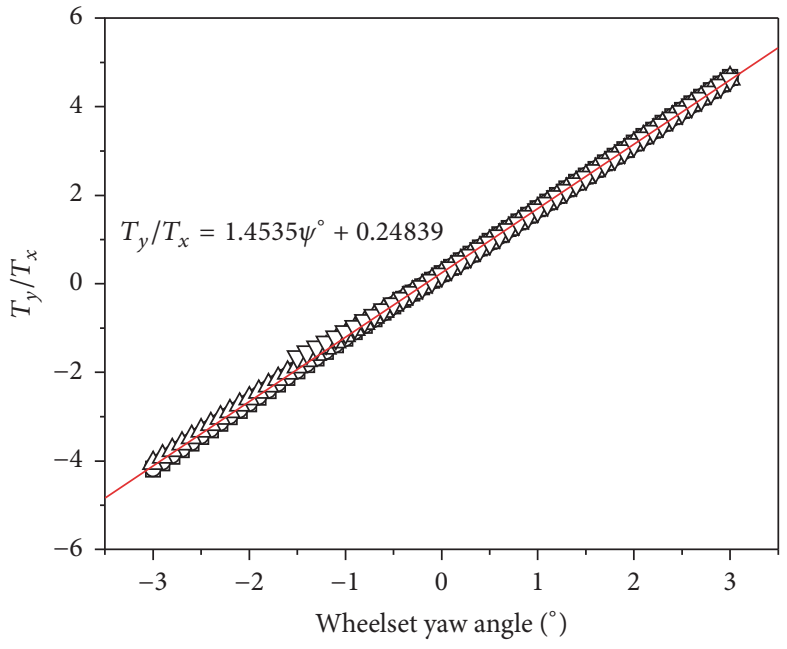

$\square \mu=0.1$

○ $\mu=0.2$ $\triangle \mu=0.3$
$\nabla \mu=0.4$

(b)

FIGURE 15: Comparison between linear fitting and theoretical result for ratio of lateral creep force to longitudinal creep force. (a) $\delta_{R}=60^{\circ}$; (b) $\delta_{R}=70^{\circ}$.

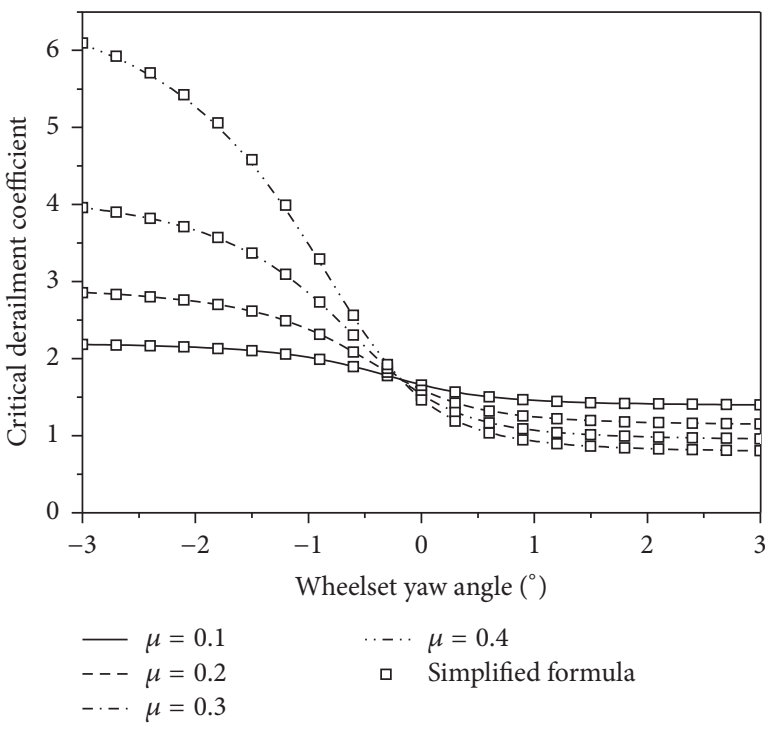

(a)

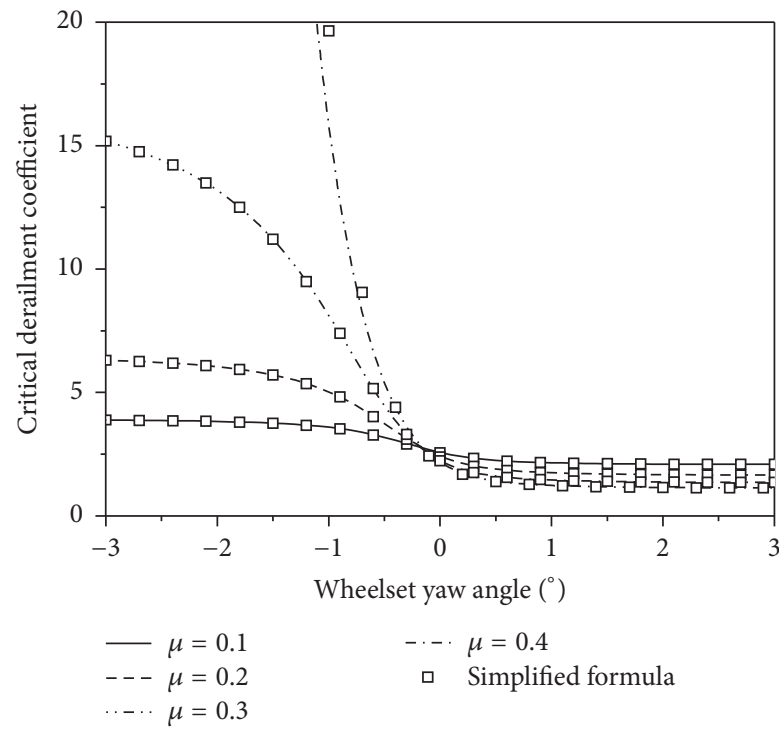

(b)

Figure 16: Comparison between critical derailment coefficients calculated according to the simplified formula and accurate calculation formula. (a) $\delta_{R}=60^{\circ}$; (b) $\delta_{R}=70^{\circ}$.

meeting the requirement of engineering application. Thus the simplified formula for wheel derailment evaluation criterion under quasistatic assumption is reasonable, feasible, and reliable.

5.3. Simplified Formula Calculation Table. As is well known, wheel-rail wear is unavoidable with the long-term operation of vehicles. The abrasion of wheel flanges and rail gauge corners can cause decrease of the maximum flange contact angle, influencing the operational safety. In order to make the simplified calculation method of critical derailment coefficients more practical, the linear fitting parameters for maximum flange contact angles within $60^{\circ} \sim 70^{\circ}$ are calculated in this paper; see Table 4.

During practical application, the proper parameters can be obtained according to the measured maximum wheel flange contact angle and the data in Table 4, and the corresponding critical derailment coefficient can be calculated according to the simplified calculation formula, reducing the working load and promoting the application of 3D derailment coefficient limit. 


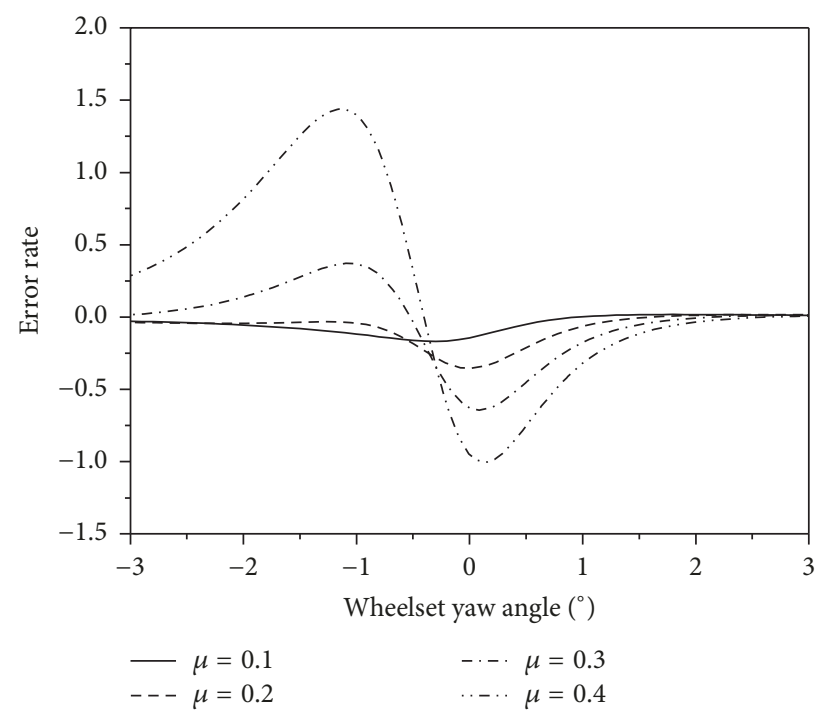

(a)

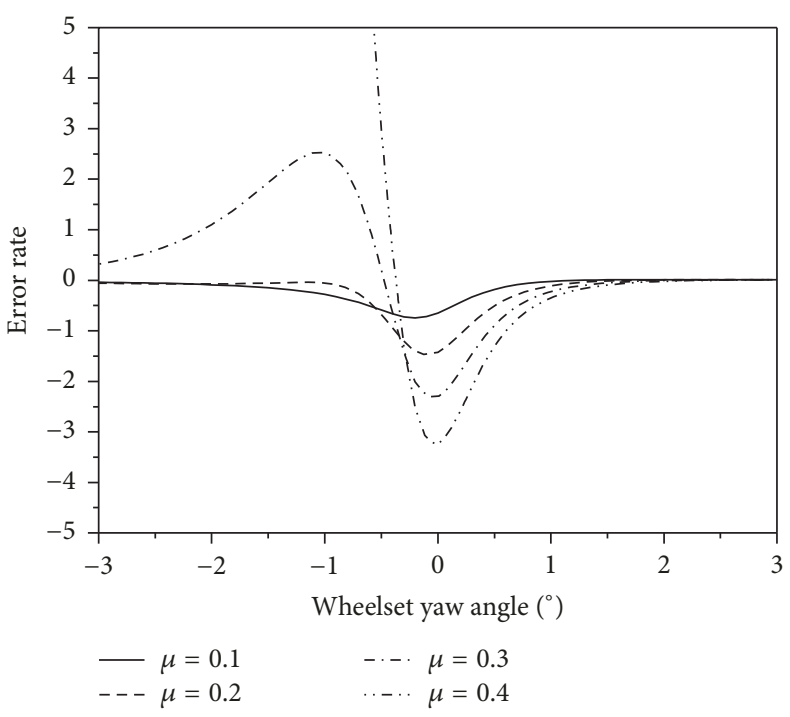

(b)

Figure 17: Analysis of error between critical derailment coefficients calculated according to the simplified formula and accurate calculation formula. (a) $\delta_{R}=60^{\circ}$; (b) $\delta_{R}=70^{\circ}$.

TABLE 4: Simplified calculation parameters for critical derailment coefficients.

\begin{tabular}{lcc}
\hline $\begin{array}{l}\text { Maximum flange } \\
\text { contact angle }\left({ }^{\circ}\right)\end{array}$ & $C$ & $D$ \\
\hline 60 & 1.00178 & 0.19069 \\
62 & 1.06522 & 0.20025 \\
64 & 1.13845 & 0.21123 \\
66 & 1.22337 & 0.22473 \\
68 & 1.3206 & 0.24474 \\
70 & 1.4535 & 0.24839 \\
\hline
\end{tabular}

\section{Conclusion}

In this paper, force analysis for $3 \mathrm{D}$ critical derailment is carried out, and a simplified method for calculating the critical derailment coefficient is deduced based on Kalker linear creep theory and Shen-Hedrick-Elkins creep theory. Based on the theoretical analysis, the following conclusions are reached.

(1) Under critical wheel derailment conditions, derailments modes of wheel-climb and wheel-slide can be distinguished according to the direction of the lateral creep force. Since the direction of lateral creep force is the same as that of wheel derailment in case of wheel-climb derailment, which can enhance the probability of derailment. Thus, derailment of wheel-climb is more likely to happen and particular attentions should be paid to it.

(2) When the wheelset yaw angle is small, the longitudinal creep force will account for a large portion of the tangential force of wheel-rail contact patches. That means if its influence on wheel derailment is neglected, the calculated critical derailment coefficient will be relatively low, further proving that critical Nadal derailment coefficients are conservative in evaluating wheel derailment under small wheelset yaw angles.

(3) Wheel-rail friction coefficients and maximum wheel flange contact angles can greatly influence the wheel derailment coefficient limit. Decrease of wheel-rail friction coefficient is helpful in avoiding wheel-climb derailment, but it can cause a decrease of the limit of wheel-slide derailment at the same time. Thus, thorough calculation should be carried out when trying to prevent wheel-slide derailment by decreasing the wheel-rail friction coefficient in order to prevent wheel-climb derailment.

(4) Under critical conditions of quasistatic wheel derailment, the tangential force within a wheel-rail contact patch calculated under different friction coefficients, maximum flange contact angles, and net wheel loads is analyzed according to the Kalker linear creep theory and Shen-HedrickElkins creep theory. Results show that the creep force within the wheel-rail contact patch has saturated and matched the Coulomb friction law under these conditions.

(5) Hence a simplified method for calculating critical derailment coefficients is presented through linearly fitting the ratio of the lateral creep force to the longitudinal creep force, as inspired by numerous calculation. The error rate for the results calculated according to the simplified formula can be kept within $\pm 5 \%$ when compared to that calculated according to the accurate formula, indicating that it is reliable and meets requirements of engineering application.

\section{Conflicts of Interest}

The authors declared that there are no conflicts of interest in their submitted paper. 


\section{Acknowledgments}

The present work has been supported by the National Natural Science Foundation of China (51425804 and 51608458) and the Project of the Ministry of Education "Chun Hui Plan" (Z2016165).

\section{References}

[1] F. J. Nadal, "Theorie de la stabilite des locomotives," Vve C. Dunod, 1896.

[2] A. O. Gilchrist and B. V. Brickle, "A Re-Examination of the Proneness to Derailment of a Railway Wheel-Set," Journal of Mechanical Engineering Science, vol. 18, no. 3, pp. 131-141, 2006.

[3] L. M. Sweet and A. Karmel, "Evaluation of time-duration dependent wheel load criteria for wheelclimb derailment," Journal of Dynamic Systems, Measurement, and Control, vol. 103, no. 3, pp. 219-227, 1981.

[4] A. Karmel, Analytical and experimental studies of derailment processes of railway vehicles, Princeton University, Princeton, NJ, USA, 1982.

[5] A. Karmel and L. M. Sweet, "Wheelset Mechanics During Wheelclimb Derailment," Journal of Applied Mechanics, vol. 51, no. 3, p. 680, 1984.

[6] H. Weinstock, "Wheel climb derailment criteria for evaluation of rail vehicle safety," in Proceedings of the ASME winter annual meeting, p. 1, 1984.

[7] W. C. Shust and J. A. Elkins, "Wheel forces during flange climb Part I - track loading vehicle tests," in Proceedings of the 1997 IEEE/ASME Joint Railroad Conference, pp. 137-147, March 1997.

[8] J. A. Elkins and W. C. Shust, "Wheel forces during flange climb Part II - NUCARS simulations," in Proceedings of the 1997 IEEE/ASME Joint Railroad Conference, pp. 149-156, March 1997.

[9] R. S. Barbosa, "A 3D contact force safety criterion for flange climb derailment of a railway wheel," Vehicle System Dynamics, vol. 42, no. 5, pp. 289-300, 2004.

[10] R. S. Barbosa, "Safety of a railway wheelset - Derailment simulation with increasing lateral force," Vehicle System Dynamics, vol. 47, no. 12, pp. 1493-1510, 2009.

[11] F. Braghin, S. Bruni, and G. Diana, "Experimental and numerical investigation on the derailment of a railway wheelset with solid axle," Vehicle System Dynamics, vol. 44, no. 4, pp. 305-325, 2006.

[12] J. Zeng and P. Wu, "Study on the wheel/rail interaction and derailment safety," Wear, vol. 265, no. 9-10, pp. 1452-1459, 2008.

[13] C.-M. Kuo and C.-C. Lin, "Analysis of derailment criteria," Proceedings of the Institution of Mechanical Engineers, Part F: Journal of Rail and Rapid Transit, vol. 230, no. 4, pp. 1158-1163, 2015.

[14] J. Zeng and Q. H. Guan, "Study on flange climb derailment criteria of a railway wheelset," Vehicle System Dynamics, vol. 46, no. 3, pp. 239-251, 2008.

[15] J. J. Kalker, Three-Dimensional Elastic Bodies in Rolling Contact, vol. 2, Kluwer Academic Publishers, Dordrecht, The Netherlands, 1990.

[16] Z. Y. Shen, J. K. Hedrick, and J. A. Elkins, "A comparison of alternative creep force models for rail vehicle dynamic analysis," Vehicle System Dynamics, vol. 12, no. 1-3, pp. 79-78, 1983. 


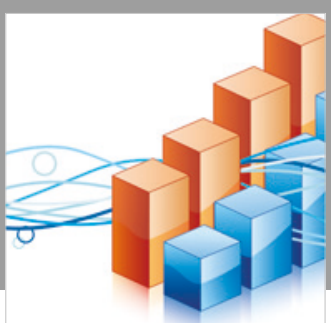

Advances in

Operations Research

\section{-n-m}
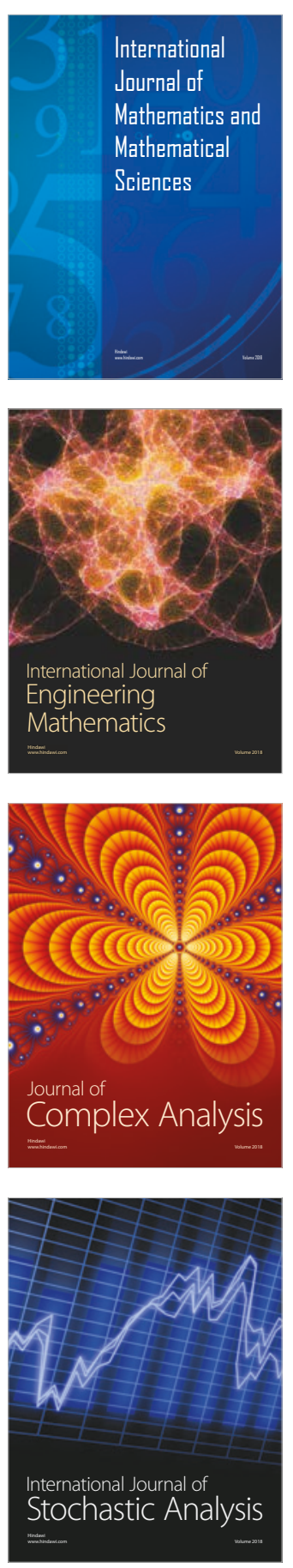
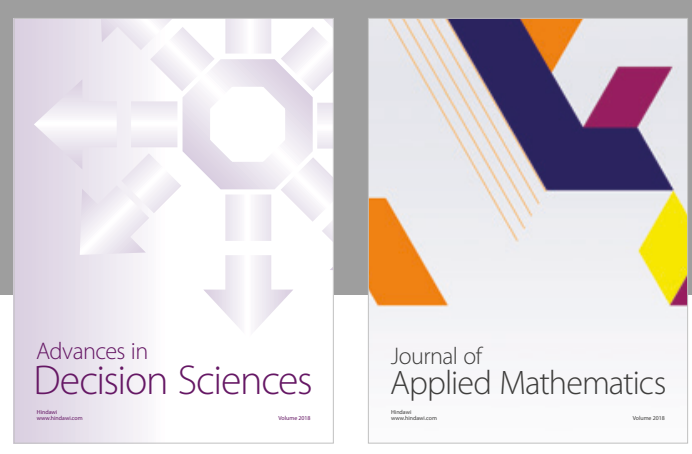

Journal of

Applied Mathematics
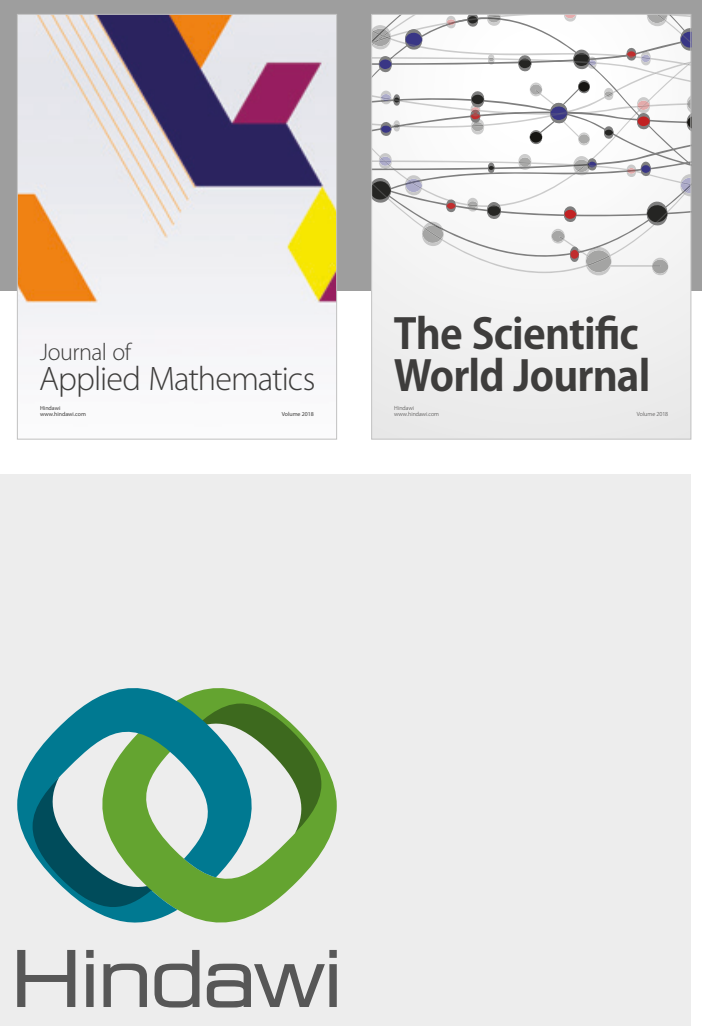

Submit your manuscripts at

www.hindawi.com

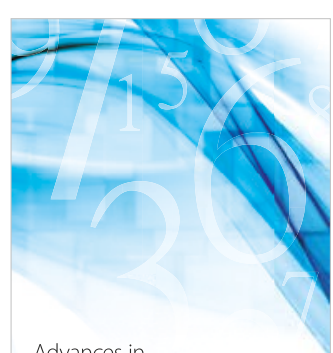

Advances in
Numerical Analysis
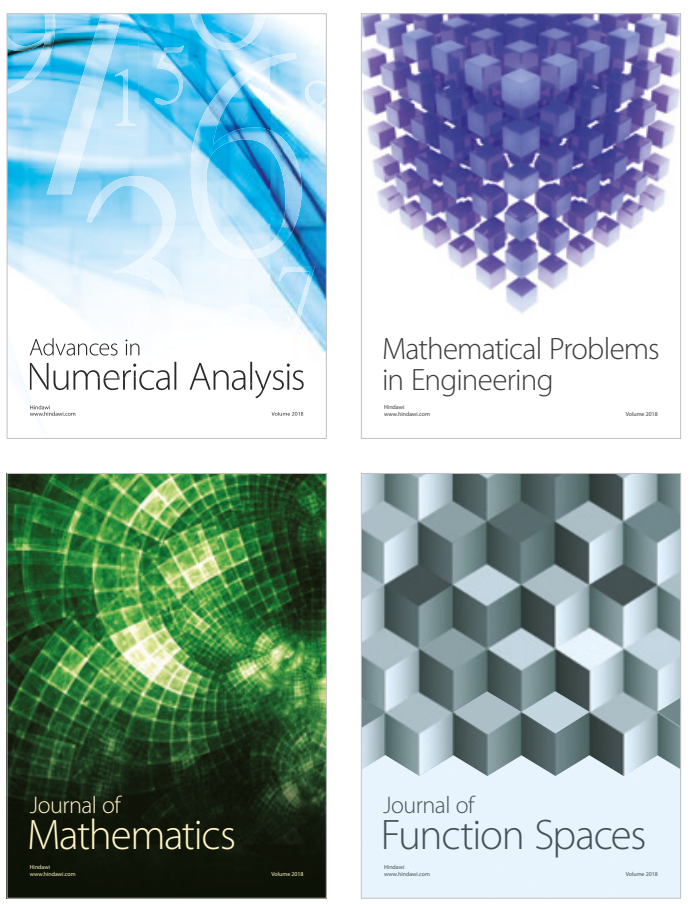

Mathematical Problems in Engineering

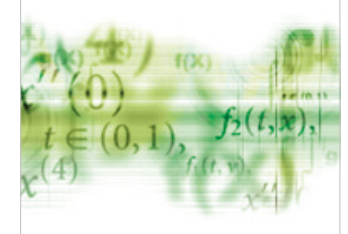

International Journal of

Differential Equations

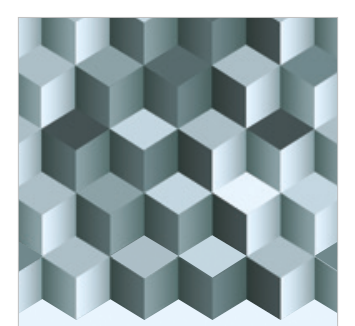

Journal of

Function Spaces

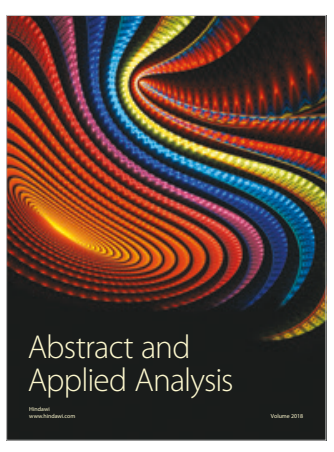

The Scientific

World Journal

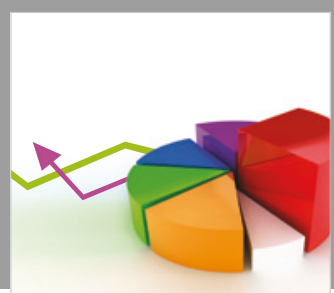

Journal of

Probability and Statistics
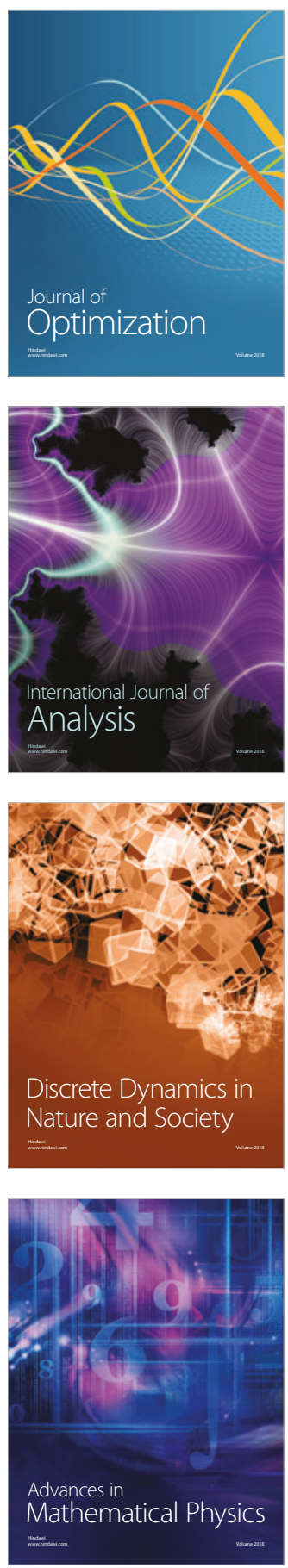